\title{
Dialogremos, Nuevo Modelo de Evaluación Docente en Educación Superior
}

\section{Dialogremos, a Novel Model for Teaching Evaluation in Higher Education}

María de las Mercedes Iglesias Sobero *, Javier Loredo Enríquez, Virginia Isidra Martínez Cruz, Raúl Romero Lara, Francisco Alvarado García y Mariana Sánchez Saldaña

Universidad Iberoamericana, México

\section{DESCRIPTORES:}

Evaluación docente

Modelo de evaluación

Educación superior

Mejora continua

Instrumentos de evaluación

\begin{abstract}
RESUMEN:
Ante la necesidad de mejorar cada vez más la evaluación de la docencia y soportarla en un proceso claro, transparente y objetivo, el presente artículo tiene como propósito dar a conocer el trabajo que se realizó en una Institución de Educación Superior para la generación de un modelo innovador de evaluación docente, que cumple con principios y características que lo identifican, pone la persona del docente en el centro del proceso, revaloriza su práctica docente, la contextualiza en una institución y se orienta a la mejora continua. Se describen las etapas para el diseño de los instrumentos a partir de una metodología mixta, que recurrió a encuestas, análisis estadísticos y grupos focales con profesores, estudiantes y autoridades. Entre los resultados destaca el diseño de un modelo de evaluación docente innovador e integral y varios instrumentos que se derivan de él y que fueron diseñados de manera diferenciada según el nivel educativo y tipo de asignatura.
\end{abstract}

\section{KEYWORDS:}

Teaching evaluation

Evaluation model

Higher education

Continuous improvement

Evaluation instruments

\section{ABSTRACT:}

There is a continuous necessity to improve and support the evaluation of teaching in a clear transparent and objective way. This article aims to present the work performed to develop a novel model for teaching evaluation at a Higher Education Institution. This model is unique due to its principles and characteristics, such as the placement of the teacher at the centre of the evaluation and the recognition of the value of the teaching practice. The model is built within the context of an institution and is oriented towards continuous improvement. This paper describes the steps taken to design the instruments based on a mixed methodology which included polling, statistical analysis and focal groups with professors, students and university administrators. What stands out among the results is the innovative and intrinsic design of the model of teaching evaluation and the various instruments derived from it; which were distinctly designed for each educational level and subject area. 


\section{Introducción al tema de la evaluación docente}

La evaluación de la docencia no es un tema nuevo, ya que podemos rastrear su origen internacional, aunque diferenciado, a mediados del siglo XX. En América Latina toma más fuerza en la década de los 90's, aunque en ciertos países solo se usa para educación básica, mientras en otros ya se ha extendido para educación media y superior.

Se le reconocen al menos dos funciones: la orientada al control y la de la búsqueda de la mejora (Ardoino, 2000); es en esta última que se ubica este artículo.

Con el propósito de promover un cambio en su sistema de evaluación docente, la Universidad Iberoamericana Ciudad de México (Ibero) integró un grupo de especialistas para revisar en profundidad el enfoque de las prácticas e instrumentos de evaluación docente y generar una propuesta de evaluación de la docencia cuya aplicación generara información diagnóstica valiosa para impulsar el desarrollo y consolidación de la planta docente.

El propósito de este trabajo es dar a conocer la propuesta de un nuevo modelo de evaluación docente que fue diseñado, desarrollado e implementado para la Ibero, presentando sus fundamentos teóricos, principios, características e instrumentos, así como el proceso metodológico que se siguió para su creación. Más adelante, con la lectura detallada de los elementos mencionados, se verá con claridad que el nuevo modelo se ubica en el paradigma de la evaluación formativa.

El modelo denominado Dialogremos busca que, mediante la evaluación docente, profesores y profesoras reflexionen sobre su práctica en el aula y mejoren su conocimiento tanto de sí como docentes, como de sus acciones. Para lograrlo se recurre a varios instrumentos diseñados con base en las características y principios del modelo, con la participación de la comunidad de estudiantes, docentes y autoridades.

También se da a conocer la estrategia metodológica que se siguió para el diseño y validación de sus instrumentos mediante análisis métricos de confiabilidad y validez, así como por medio de grupos focales y entrevistas con varios sectores de la comunidad educativa. Se pilotearon los instrumentos con muestras amplias de la comunidad estudiantil y docente.

La extensión de este artículo no permite presentar los instrumentos en su forma íntegra (formato y contenido) por lo que decidimos mostrar ejemplos de dos de los más representativos; Dialogremos Apreciación Estudiantil y Dialogremos Autoevaluación del docente, con sus respectivos reportes.

Finalmente es importante reiterar que esta propuesta surge como necesidad institucional, lo que ha permitido su implementación, por lo que no podemos dejar de reconocer el interés y el apoyo de la Universidad Iberoamericana, Ciudad de México para desarrollar el proyecto en todas sus fases, y lo más importante, el haber querido instaurar un modelo de evaluación docente que cuide al profesor, que atienda al estudiante, que informe a las autoridades y que sea un modelo que tiene como principal característica la retroalimentación para impulsar la reflexión, el diálogo y la mejora continua.

\section{Fundamentación del modelo}

La docencia, como tarea compleja, multireferencial y multidimensional, ha sido entendida de diferentes formas en los distintos momentos y contextos en que se ha desarrollado, de ahí la dificultad para llegar a una visión unificada sobre la función docente (García-Cabrero et al., 2011).

Lo mismo ocurre con la evaluación de la práctica docente que, por ser un fenómeno relativamente nuevo y complejo, ha adoptado los planteamientos teóricos de la evaluación educativa (García et al., 2011; Jornet et al., 2020; Loredo y Romero, 2012).

Lo anterior nos sitúa ante una ausencia de bases conceptuales que orienten el objeto de estudio, los métodos y los procedimientos para evaluar el trabajo docente, por lo que usualmente se han privilegiado los aspectos técnicos: indicadores, criterios y procedimientos planteados desde el sentido común, lo que ha convertido esta tarea en un trabajo de ensayo y error. 
Aunque en la actualidad, la evaluación se ha convertido en una moda presente en las políticas educativas de muchos países para mejorar la calidad de la educación, aún falta precisar el modelo de docencia que será evaluado en cada nivel educativo, tipo de institución y país. Tampoco se han hecho explícitos los fundamentos, fines, procedimientos para el diseño de una evaluación integral del trabajo en las aulas y el uso que se dará a los resultados; lo cual se ve reflejado en políticas institucionales de evaluación de la docencia que no han tenido efectos claros en la mejora de la calidad educativa (Rueda et al., 2011).

La falta de participación de los docentes durante el proceso de evaluación de su práctica, desde su diseño hasta el uso de sus resultados, conduce al desconocimiento de los instrumentos, criterios y mecanismos bajo los cuales son evaluados (Ochoa y Moya, 2019). Esto genera no sólo posturas de incertidumbre, desconfianza y resistencia, sino también evita un compromiso por parte de ellos (Salazar, 2010).

Diversos autores muestran que en muchas instituciones se realiza la continua vinculación de la evaluación con procesos administrativos, de financiamiento y de control, decisiones sobre promoción, permanencia, definición salarial, estímulos económicos, y reconocimiento. Esto aleja a la evaluación de una orientación al perfeccionamiento (función formativa) y claramente la orienta al control (Arbesú y García Garduño, 2017; De Dios et al., 2017; Rueda, 2018; Sierra, 2020) por lo que no es raro encontrar poca coincidencia entre las intenciones declaradas de la evaluación de la docencia y el uso de los resultados (Ford y Hewitt, 2020; Gómez y Valdés, 2019; Ochoa y Moya, 2019; Olarte et al., 2019).

Tanto en la literatura especializada, como en las discusiones con expertos (Montoya et al., 2014; Rueda, 2018) se observa que son pocas las instituciones de educación superior (IES) que cuentan con un sistema de evaluación de la docencia; la mayoría sólo emplean un instrumento aislado.

La carencia de modelos de evaluación de la docencia coherentes con un proyecto nacional o institucional que definan perfiles, propósitos, procedimientos, indicadores e instrumentos convierten a la evaluación en acciones de poco impacto real (Salazar, 2010).

En cuanto a los instrumentos de evaluación empleados, se ve una clara tendencia por el uso de cuestionarios de opinión por parte de los estudiantes (Contreras, 2018; Rueda et al., 2010).

Asimismo, pareciera que las cualidades de una docencia eficaz son las mismas para todos, independientemente de países, instituciones, modelos o niveles educativos, áreas de conocimiento, tipo de intervención didáctica o modalidad de la materia, ya que para el diseño de los instrumentos se retoman de la literatura especializada, ciertos ítems o cuestionarios completos, sin considerar el contexto de la práctica docente y la poca utilidad de los resultados para mejorarla (Iglesias y Loredo, 2017; Romero y Martínez, 2017; Samino y Rivero, 2018).

Con respecto a los usos de la evaluación, se encontró la escasa o nula comunicación de los resultados a los docentes, la carencia de espacios de retroalimentación y reflexión, y la desvinculación de acciones formativas, de capacitación y actualización con las necesidades detectadas (Sierra, 2020; Rueda et al., 2010). En muchas IES la oferta es definida por las autoridades. Asimismo, se reconoce que no existen programas de seguimiento para dar continuidad a la mejora de la práctica (Parra et al., 2017).

Rueda y otros (2010) identificaron que las IES no recurren a la información obtenida para realizar estudios comparativos o analizar la evolución o cambio de los docentes. Esto refleja que los procesos de evaluación son eventos aislados que solo tienen valor por el período de aplicación.

Abordar la problemática de esta evaluación desde la perspectiva del docente resulta indispensable, no sólo por su importancia como participante activo en el proceso, sino además porque entre las dificultades detectadas, se encuentran actitudes de resistencia, simulación, duda, descalificación de procesos y estudiantes, desconfianza y falta de compromiso.

A partir de esta revisión de la literatura el equipo de trabajo se propuso desarrollar un modelo de evaluación que recuperara información de diversos actores (estudiantes, docentes y coordinadores), de tal forma que Dialogremos sea un modelo holístico de evaluación docente.

Para lo anterior se partió de algunos conceptos básicos: 
Entendemos la docencia como una de las funciones básicas de la universidad dirigida a la formación de profesionistas e investigadores de gran calidad humana e intelectual, competentes a nivel nacional e internacional, comprometidos en el mayor servicio a los demás, e inspirados por valores auténticamente humanos, sociales y trascendentes. El papel de los docentes consiste en guiar al estudiantado hacia un aprendizaje situado y colaborativo, que promueva la autonomía y la movilización de conocimientos, habilidades, actitudes y principios con sentido personal y social (Universidad Iberoamericana, 2010, 2018). Así, la docencia es el medio por el cual los profesores acompañan a los estudiantes en su crecimiento y desarrollo, medio que no puede reducirse simplemente a una metodología, debe incluir una perspectiva del mundo y una visión de la persona humana que se quiere formar para los demás (Duplá, 2000; Kolvenbach y Hans, 1993). Es también una práctica social que se da en momentos y contextos determinados.

El docente debe buscar generar un ambiente que favorezca la participación y el diálogo basado en relaciones de respeto y cercanía, donde hay normas y consecuencias claras que forman en la responsabilidad y la solidaridad. La finalidad de la labor docente es la formación integral de la persona que considera la formación académica de calidad, la promoción de la madurez emocional, la responsabilidad ética, la experiencia de trascendencia, y su realización personal en el servicio a la sociedad (Universidad Iberoamericana, 2013). Concebimos al aprendizaje como un proceso de construcción social y personal, en el que el estudiante atiende, percibe, organiza y relaciona los nuevos conocimientos, para construir una realidad compartida y darle un sentido propio que integra en su estructura de personalidad (Vigotsky, 1979).

Aprender implica que la persona tome conciencia y se apropie de sus procesos para elegir las mejores estrategias de aprendizaje y autorregulación (Posner, 2004).

El aprendizaje parte de esquemas, saberes y experiencias previas de los estudiantes; como proceso inseparable del contexto en el que se produce, está basado en experiencias específicas. Y tiene lugar mediante la interacción con otros en un contexto determinado. Se produce mediante la reflexión sobre la experiencia de aprendizaje, a partir del diálogo con otros para negociar significados, representaciones y valores, con la intención de reconstruir significados en un espacio y tiempo concretos (Campos, 2004).

Con base en estas visiones sobre docencia y aprendizaje, la evaluación de la docencia es un proceso continuo y permanente de reflexión sistemática sobre la actividad del docente; es una actuación crítica positiva que busca mejores resultados de aprendizaje por lo que su fin principal es la mejora de la enseñanza.

El proceso de evaluación tiene el potencial para ser formador en la medida en que proporciona insumos significativos para la reflexión intencional, sistemática, vinculada con procesos participativos y democráticos que favorezcan que los profesores identifiquen áreas de oportunidad para mejorar su labor educativa con sus estudiantes. Otro elemento importante es involucrar la creatividad e innovación en las acciones que serán emprendidas por el docente en el siguiente periodo para ofrecer recursos más atractivos a los alumnos (Domingo, 2013; Schön, 1998). Así, la evaluación docente es un proceso sistemático para recoger información válida y confiable de evidencias útiles, oportunas y pertinentes sobre el desempeño del docente, para emitir un juicio de valor basado en determinados criterios, que fundamente la toma de decisiones sobre el hecho evaluado. Permite también definir acciones futuras, con el fin de comprender el fenómeno educativo y mejorar la enseñanza y el aprendizaje.

\subsection{Dimensiones de la docencia}

A partir de los estudios sobre contenidos, enfoques y elementos que se incluyen en las prácticas de evaluación de la docencia (Loredo y Romero, 2012; Rueda et al., 2010) y con base en los elementos planteados en la Filosofía educativa (1985), el modelo educativo de la Ibero y documentos filosóficos de la Compañía de Jesús (Kolvenbach, 1993, 2007; Proyecto Educativo Común de la Compañía de Jesús en América Latina - PEC, 2005), se integraron siete dimensiones de la docencia que son la base del modelo Dialogremos (Cuadro 1). 
Cuadro 1.

Dimensiones de la Docencia

\begin{tabular}{|c|c|}
\hline Dimensión & Descripción \\
\hline $\begin{array}{l}\text { Competencias } \\
\text { Profesionales }\end{array}$ & $\begin{array}{l}\text { Conocimientos disciplinares, características de comportamiento y actitudes del docente } \\
\text { desarrolladas a lo largo de su proceso formativo y experiencia profesional que le permiten } \\
\text { promover el desarrollo de las competencias de los estudiantes a través de la docencia en el } \\
\text { contexto de los valores institucionales. }\end{array}$ \\
\hline Planeación & $\begin{array}{l}\text { Habilidad del docente para diseñar los procesos de enseñanza y evaluación del aprendizaje } \\
\text { que propicien el desarrollo de competencias por parte de los estudiantes atendiendo al mo- } \\
\text { delo educativo institucional, el contexto social y las necesidades y los aprendizajes previos de } \\
\text { los estudiantes, considerando la ubicación de la materia en el plan de estudios. }\end{array}$ \\
\hline $\begin{array}{l}\text { Estrategias de } \\
\text { enseñanza }\end{array}$ & $\begin{array}{l}\text { Efectividad del docente para que sus estudiantes desarrollen competencias, construyan } \\
\text { conocimiento y desarrollen habilidades genéricas y profesionales a partir de la interacción } \\
\text { humana utilizando recursos didácticos y tecnológicos pertinentes al contexto del programa y } \\
\text { al nivel universitario. }\end{array}$ \\
\hline $\begin{array}{l}\text { Ambiente de } \\
\text { aprendizaje }\end{array}$ & $\begin{array}{l}\text { Habilidades del docente para propiciar interacciones positivas entre estudiantes y de éstos } \\
\text { con el docente a partir de normas claras basadas en la justicia, el respeto, la responsabilidad, } \\
\text { el diálogo y la inclusión. }\end{array}$ \\
\hline $\begin{array}{l}\text { Evaluación del } \\
\text { Aprendizaje }\end{array}$ & $\begin{array}{l}\text { Capacidad del docente para realizar un proceso sistemático de recolección de información } \\
\text { útil, oportuna y pertinente sobre los aprendizajes de los estudiantes que permita retroali- } \\
\text { mentar su desempeño a partir de criterios claros que sirvan para orientar los aprendizajes y } \\
\text { fundamente una toma de decisiones objetiva, coherente y justa. }\end{array}$ \\
\hline Ética y Valores & $\begin{array}{l}\text { Capacidad del docente para promover un comportamiento ético y el ejercicio de la libertad y } \\
\text { la justicia, así como para vivenciar los valores institucionales en el aula y fuera de ella. }\end{array}$ \\
\hline $\begin{array}{l}\text { Compromiso } \\
\text { Social }\end{array}$ & $\begin{array}{l}\text { Capacidad del docente para formar en el estudiante conciencia y actitudes para asumir un } \\
\text { compromiso social que promueva una sociedad más justa, solidaria, libre, incluyente, pro- } \\
\text { ductiva y pacífica. }\end{array}$ \\
\hline
\end{tabular}

Nota. Elaboración propia.

\subsection{Principios}

El modelo responde a una serie de principios rectores, que dan cuenta de la Filosofía Institucional:

- Humanista, es coherente con la filosofía y modelo educativo de la Universidad.

- Formativo, principalmente orientado a la mejora continua y al perfeccionamiento de la práctica docente (Cabarrús, 2003; Hattie y Clarke, 2018; Zabalza, 2012).

- Transparente, se caracteriza por establecer con precisión: dimensiones, indicadores a evaluar, instrumentos, forma de aplicación de estos, consecuencias y acciones de mejora.

- Revaloriza la práctica docente como un medio de reconocimiento de la acción del profesorado en el aula.

- Innovador, porque introduce novedades que buscan modificar elementos ya existentes con el fin de mejorarlos.

- Científico, se sustenta en un trabajo riguroso apoyado por una reflexión teórica e investigación empírica.

- Respeta al docente como persona, ya que promueve el conocimiento de uno mismo, el cuidado de la persona y la toma de decisiones para actuar en libertad (Kolvenbach, 2007; Loredo, 2000).

- Genera confianza debido a la transparencia de sus procesos y uso de resultados, al no tener un propósito punitivo. 


\subsection{Características}

Con base en todos estos elementos, se establecieron las características esperadas del modelo de evaluación:

- Contextualizado: diseñado específicamente para las características y principios de la Ibero, al estar fundamentado en el ideario de la universidad, la Pedagogía Ignaciana, el modelo educativo, el perfil ideal del profesor, el perfil docente por competencias y la planeación estratégica 2030, entre otros.

- Es integral, en tanto que contempla una visión amplia de la práctica docente y el abordaje desde la perspectiva de diferentes actores mediante diversos instrumentos diseñados según las características de cada nivel educativo y modalidades de intervención y procesos pedagógicos. Parte de la evaluación e integra la retroalimentación y las acciones de mejora.

- Está centrado en la persona del/la docente y en su labor como gestor y facilitador del aprendizaje.

- Es participativo al incorporar la colaboración de la comunidad educativa en las diversas etapas del diseño y validación de los instrumentos.

- Permite la triangulación de información al analizar los resultados de diversos instrumentos aplicados a distintos actores.

- Está orientado a la mejora continua de la práctica docente en una constante búsqueda de mejores aprendizajes de los estudiantes. Permite enfocar los esfuerzos en la formación y superación en un plan articulado y sistemático para consolidar una planta docente de calidad.

- Incorpora la metaevaluación ya que sus instrumentos, mecanismos y procesos se evaluarán periódicamente, en un proceso vivo y dinámico de transformación, que permanecerá en continua revisión para su mejora y actualización.

- Promueve la Cultura de la Evaluación, que por medio de la reflexión y el análisis revalore la función docente, mejorando los procesos de planeación, evaluación y formación.

\subsection{Objetivo del modelo}

El modelo busca evaluar al docente de forma integral, con el fin de orientarlo a la mejora continua y a la innovación de la práctica docente, que a partir de los resultados de la evaluación tenga impacto en el incremento de la cantidad y calidad de los aprendizajes de los estudiantes, respetando y recuperando las características de la Universidad.

La finalidad del modelo Dialogremos es contar con información válida, confiable, sistemática y oportuna del desempeño del profesorado, desde un enfoque comprehensivo, que permita reflexionar, dialogar y comprender los procesos de enseñanza y aprendizaje, considerando la visión de distintos actores.

Dialogremos está orientado a que predomine el afecto, el respeto y la armonía entre docentes y estudiantes para que vivan una cultura de la evaluación y la mejora continua.

\section{El desarrollo del modelo y sus instrumentos}

Tanto para el desarrollo del modelo como para el diseño de sus instrumentos, se tomaron en cuenta las aportaciones de docentes y estudiantes, así como la asesoría de expertos en la materia, procedentes de universidades mexicanas, europeas y latinoamericanas. 
Se realizaron dos encuestas. La primera, respondida por el $60 \%$ del personal docente, tenía como intención identificar su opinión frente a los propósitos, procedimientos, instrumentos y usos de los resultados de la evaluación de su desempeño, así como su disponibilidad para participar en el proceso de construcción del modelo y validación de los instrumentos. La segunda, sometía ante la comunidad de docentes y estudiantes, el inventario de elementos evaluables, para que señalaran aquellos que consideraban que debían integrarse en los instrumentos. Esta segunda encuesta tuvo respuesta del $40 \%$ de la planta académica y del 10\% de los estudiantes.

Con base en estos resultados, se integraron los instrumentos de apreciación estudiantil (IAE) en cuatro versiones de formato de respuesta diferentes, cuyos ítems fueron sometidos a la validación de jueces expertos, y al análisis mediante entrevistas cognitivas 1realizadas con estudiantes.

Posteriormente se diseñó un instrumento de autoevaluación para los docentes que propiciara la reflexión y el análisis sobre su propio desempeño; que fue enriquecido con la retroalimentación de docentes participantes en grupos focales.

Se invitó a estudiantes y docentes del Departamento de Diseño a que presentaran propuestas tanto del nombre como de la imagen gráfica del modelo, que fueran significativas para la comunidad y que contribuyeran a comunicar su vocación de diálogo y colaboración para mejorar los procesos educativos. La propuesta elegida, Dialogremos, da nombre e identidad al modelo.

Los instrumentos de apreciación estudiantil y de autoevaluación docente resultantes se pilotearon durante el verano de 2019, mediante 4.809 aplicaciones con estudiantes y 302 con docentes que expresaron su opinión sobre la aplicabilidad del instrumento en su asignatura. Se realizaron análisis métricos de confiabilidad (Alfa de Cronbach) y validez (Análisis factorial exploratorio y confirmatorio), así como análisis de discriminación y varianza por pregunta. A partir de los resultados obtenidos, se realizaron ajustes y se efectuó un segundo pilotaje del IAE en septiembre de 2019, con 1.325 estudiantes y 91 docentes.

En una siguiente etapa, se realizaron nueve grupos focales con la participación de más de 100 docentes, para el desarrollo de instrumentos específicos para distintas modalidades de asignatura (cursos teórico práctico, talleres, laboratorios, prácticas profesionales, servicio social, asignaturas en línea, seminarios y tutoría de posgrado) y niveles educativos (Técnico superior universitario, licenciatura y posgrado). Esto permitió contar con instrumentos diferenciados que conservan la fundamentación de las dimensiones y estructura general, pero que abordan aspectos específicos de la docencia para cada nivel y modalidad.

Los instrumentos diferenciados por modalidad y la autoevaluación se aplicaron a toda la comunidad a partir de noviembre de 2019. En esta aplicación, además de responder cada uno de los ítems, tanto docentes como estudiantes tuvieron la oportunidad de valorar la pertinencia de cada uno de los reactivos con respecto a la modalidad de la asignatura y las características de los tres niveles educativos, lo que nos permitió contar con información complementaria proveniente del total de la población.

Después de la aplicación censal se estimaron las características psicométricas para cada instrumento, adicionalmente se incluyeron análisis de discriminación y varianza. En el Cuadro 2 se muestra un ejemplo para el instrumento de Apreciación Estudiantil.

1 Según Caicedo y Zalazar-Jaime (2018), las Entrevistas Cognitivas "son método para identificar y corregir los problemas relacionados con las respuestas a un ítem de un cuestionario. La idea básica consiste en entender por qué una persona responde, de qué manera lo hace y determinar de qué modo se comportará. Es decir, proporcionan evidencias de validez basadas en el proceso de respuesta”. 
Cuadro 2

Ejemplo de características psicométricas Instrumento de Licenciatura Teórico- Práctico

\begin{tabular}{lccc}
\hline \multicolumn{1}{c}{ Dimensión } & $\begin{array}{c}\text { Confiabilidad Alpha de } \\
\text { Cronbach }\end{array}$ & $\begin{array}{c}\text { Validez Análisis Factorial } \\
\text { Exploratorio }\end{array}$ & $\begin{array}{c}\text { Validez Análisis Factorial } \\
\text { Confirmatorio }\end{array}$ \\
\hline $\begin{array}{l}\text { Planeación* } \\
\begin{array}{l}\text { Estrategias de } \\
\text { enseñanza y } \\
\text { aprendizaje }\end{array}\end{array}$ &, 695 & $53 \%$ & 1,053 \\
$\begin{array}{l}\text { Ambiente de } \\
\text { aprendizaje }\end{array}$ &, 881 & $65 \%$ &, 957 \\
$\begin{array}{l}\text { Evaluación } \\
\text { Competencias } \\
\text { Profesionales }\end{array}$ &, 747 & $51 \%$ &, 939 \\
Ética y Valores** &, 862 & $68 \%$ &, 889 \\
$\begin{array}{l}\text { Compromiso } \\
\text { Social** }\end{array}$ &, 794 & $56 \%$ &, 951 \\
\hline
\end{tabular}

Nota.

* Se calculó a pesar de que sólo tiene dos indicadores. Los resultados son tratados por indicador.

** En los análisis se identifican como una sola dimensión. Elaboración propia.

En el caso del instrumento de Autoevaluación se realizaron análisis de: confiabilidad, discriminación, varianza y exclusivamente el análisis exploratorio para corroborar que los indicadores estuvieran abonando a la dimensión a la que pertenecían y que discriminaban. Los pesos factoriales dentro de cada dimensión oscilaron entre , 400 a , 800 y los valores de discriminación se mantuvieron entre 0.2 y 7.0, aspecto que se consideró positivo para la integración de perfiles docentes.

Para concluir esta etapa de desarrollo, se diseñaron reportes de resultados individuales, tanto del instrumento de apreciación estudiantil como del de autoevaluación, que proporcionen a los docentes no sólo los resultados de su evaluación, sino también, elementos que les permitan identificar sus fortalezas y sus áreas de oportunidad, así como sus estilos de docencia, elementos esenciales para alimentar los procesos de mejora continua de su práctica docente.

La Figura 1 muestra las etapas que se siguieron para llegar al diseño de los instrumentos.

Figura 1

Etapas del diseño de instrumentos

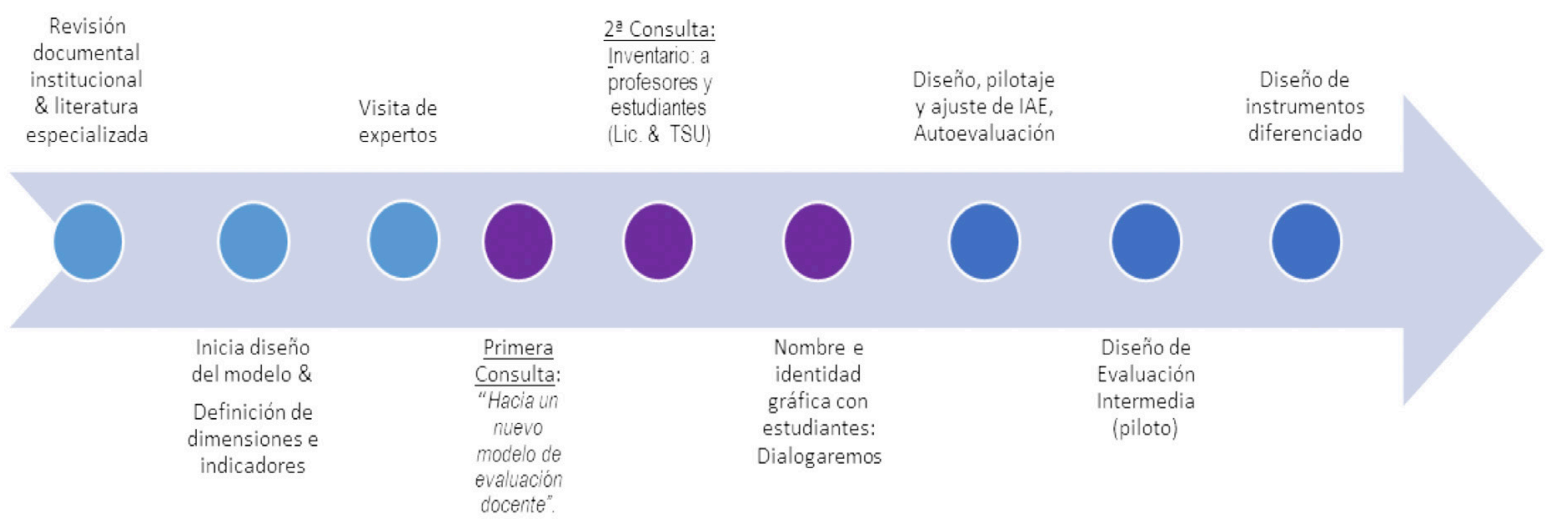

Nota. Elaboración propia. 


\subsection{Dialogremos, modelo de evaluación docente para la Universidad Iberoamericana, Ciudad de México}

El modelo Dialogremos integra la visión institucional sobre docencia y aprendizaje, las dimensiones de la docencia, la especificidad de niveles y modalidades de asignaturas, los momentos de la evaluación (diagnóstica, intermedia y formativa), la centralidad de la persona del docente, la participación de múltiples actores y la orientación hacia la mejora continua.

La Figura 2 ilustra los elementos que integran el modelo.

Figura 2

Modelo Dialogremos

DIALOGREMOS

\section{MODELO DE EVALUACIŌN DOCENTE}

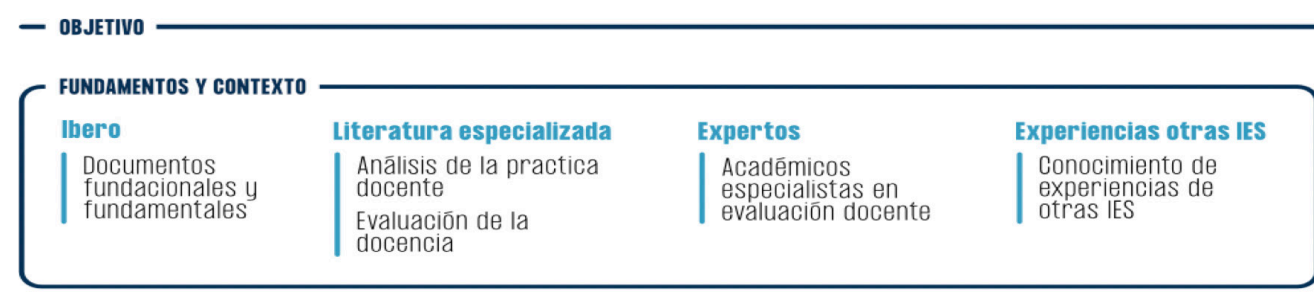

\begin{tabular}{|c|c|c|c|}
\hline \multicolumn{2}{|l|}{ PRINCIPIOS } & \\
\hline $\begin{array}{l}\text { - Humanista } \\
\text { - Formativo } \\
\text { - Transparente } \\
\text { - Revalorizador }\end{array}$ & $\begin{array}{l}\text { - Innovador } \\
\text { - Cientîfico } \\
\text { - Respeto por el docente } \\
\text { - Genera confianza }\end{array}$ & $\begin{array}{l}\text { - Dināmico } \\
\text { - Integral } \\
\text { - Participativo } \\
\text { - Contextualizado } \\
\text { - Docente } \\
\text { facilitador /gestor }\end{array}$ & $\begin{array}{l}\text { - Triangula informaciōn } \\
\text { - Plan de mejora } \\
\text { - Mejora continua } \\
\text { - Promueve cultura evaluaciōn } \\
\text { - Metaevaluaciōn }\end{array}$ \\
\hline
\end{tabular}

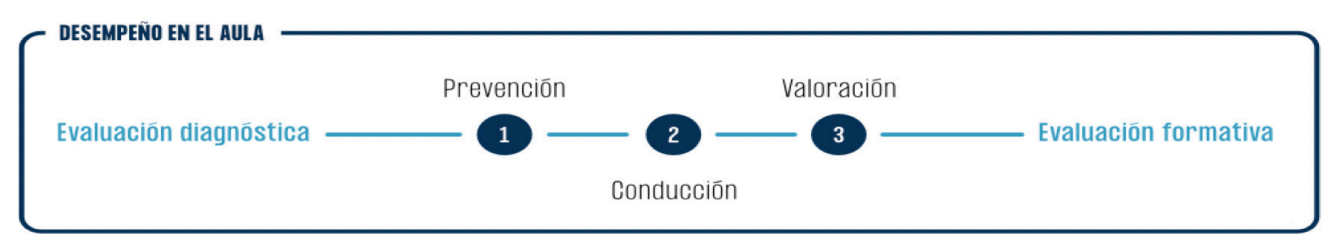

\footnotetext{
- Competencias profesionales - Ambientes de aprendizaje

- Planeaciōn del curso

- Estrategias de enseñanza

- Evaluación del aprendizaje

- Etica y valores

- Compromiso social
}

METOdOLOGÍA CUANTitativa Y CUALITATIVA

- Inventario de elementos de la prāctica docente

- Construcciōn y validaciōn

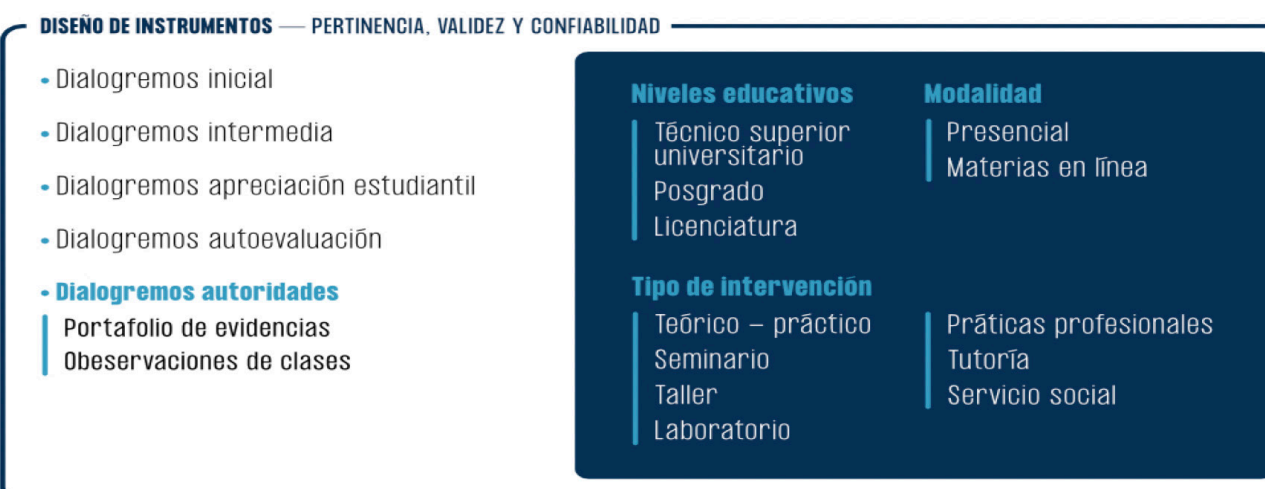

Nota. Elaboración propia. 


\section{Resultados: Las primeras aportaciones del modelo}

Como resultado de este proceso de construcción del modelo y sus instrumentos, destacamos aportaciones que resultan valiosas para el desarrollo institucional de la docencia en la Ibero:

\subsection{La diversidad de instrumentos y actores incluidos en el modelo}

Un rasgo distintivo del modelo es que incorpora la mirada de múltiples actores, cuyas aportaciones para el proceso de evaluación son recogidas por medio de diversos instrumentos, como se ilustra en el Cuadro 3 , en el que se muestra el listado de los instrumentos incluidos en el modelo, su finalidad y los actores que participan en cada uno, ya sea como respondientes o como usuarios de la información resultante.

Cuadro 3

Instrumentos, inalidad del tipo de evaluación y participantes

\begin{tabular}{|c|c|c|}
\hline $\begin{array}{c}\text { Tipo de } \\
\text { evaluación }\end{array}$ & Finalidad & Participantes \\
\hline $\begin{array}{l}\text { Dialogremos } \\
\text { inicial }\end{array}$ & $\begin{array}{l}\text { Determinar si los nuevos profesores cuentan con las } \\
\text { competencias y la formación para el ejercicio de la } \\
\text { docencia. }\end{array}$ & $\begin{array}{l}\text { Docente aspirante } \\
\text { Coordinador(a) } \\
\text { Director(a) de departamento, } \\
\text { Comisión responsable }\end{array}$ \\
\hline $\begin{array}{l}\text { Dialogremos } \\
\text { Intermedia }\end{array}$ & $\begin{array}{l}\text { Establecer un diálogo a mitad del período entre estu- } \\
\text { diantes y docentes y, docentes y coordinadores, con } \\
\text { el fin de tomar acciones de mejora en beneficio de los } \\
\text { logros de aprendizaje de los estudiantes. Asimismo, } \\
\text { fomentar la reflexión entre ellos, en una retrospectiva } \\
\text { de lo que ha sucedido en lo que va del curso. }\end{array}$ & $\begin{array}{l}\text { Docente (detonante) Estudiantes } \\
\text { (responden) }\end{array}$ \\
\hline $\begin{array}{l}\text { Dialogremos } \\
\text { Apreciación } \\
\text { Estudiantil }\end{array}$ & $\begin{array}{l}\text { Reconocer fortalezas, áreas de oportunidad y proponer } \\
\text { mejoras al desempeño de los docentes al final del perío- } \\
\text { do a partir de la apreciación de los estudiantes. }\end{array}$ & Estudiantes (responden) \\
\hline $\begin{array}{l}\text { Dialogremos } \\
\text { Autoevaluación } \\
\text { Docente }\end{array}$ & $\begin{array}{l}\text { Promover la reflexión de los docentes sobre sus expe- } \\
\text { riencias durante los cursos impartidos con base en las } \\
\text { dimensiones de la docencia a fin de identificar fortale- } \\
\text { zas y áreas de oportunidad. Asimismo, identificar los } \\
\text { elementos que caracterizan su práctica docente. }\end{array}$ & Docentes \\
\hline $\begin{array}{l}\text { Dialogremos } \\
\text { Autoridades }\end{array}$ & $\begin{array}{l}\text { Los Coordinadores valoran actitudes, acciones y partici- } \\
\text { pación del docente en tareas que contribuyen a mejorar } \\
\text { la docencia y su participación en actividades académi- } \\
\text { cas y formativas del departamento. }\end{array}$ & $\begin{array}{l}\text { Coordinador(a) o docente de tiem- } \\
\text { po completo asignado. }\end{array}$ \\
\hline $\begin{array}{l}\text { Portafolio } \\
\text { Docente }\end{array}$ & $\begin{array}{l}\text { El docente reúne evidencias de su práctica docente de } \\
\text { acuerdo con las características que la plataforma insti- } \\
\text { tucional ofrece y reflexiona en torno a su docencia. }\end{array}$ & $\begin{array}{l}\text { Docente } \\
\text { Pares }\end{array}$ \\
\hline $\begin{array}{l}\text { Observación de } \\
\text { clase por pares }\end{array}$ & $\begin{array}{l}\text { Mecanismo que permite hacer el análisis de la práctica } \\
\text { docente de un(a) profesor(a) mediante la observación } \\
\text { en el aula por parte de un par. }\end{array}$ & $\begin{array}{l}\text { Pares } \\
\text { Docente }\end{array}$ \\
\hline
\end{tabular}

Nota. Elaboración propia.

\subsubsection{Dialogremos Apreciación Estudiantil}

El Instrumento de Apreciación Estudiantil (IAE) está conformado por tres preguntas abiertas y 22 cerradas; de estas últimas, 19 pertenecen a las dimensiones de la docencia evaluadas, dos son globales y una corresponde a la pregunta control. Existen 10 versiones diferentes, según el nivel y modalidad que, aunque tienen variaciones en la redacción e incorporación de reactivos, comparten una estructura similar. A manera de ejemplo, en la Figura 3 se muestra el instrumento de Licenciatura, modalidad Teórico-Práctico. 
Figura 3

Instrumento de Apreciación Estudiantil. Nivel Licenciatura. Modalidad Teórico-Práctico

Instrucciones. Evalúa el desempeño de tu profesor(a) en esta materia. Esta información le ayudará para mejorar. Habrá preguntas abiertas y cerradas que deberás contestar de acuerdo a la escala. Reflexiona y evalúa con precisión y objetividad.

\begin{tabular}{|c|c|c|}
\hline Dimensión del reactivo & Pregunta & Opción de Respuesta \\
\hline No aplica & 1. ¿Qué hizo tu profesor(a) que te ayudó a aprender? & Abierta \\
\hline Planeación & $\begin{array}{l}\text { 2. Al preparar sus clases, toma en cuenta nuestras necesidades de aprendizaje } \\
\text { durante el curso }\end{array}$ & \multirow{10}{*}{$\begin{array}{l}\text { Escala Likert } \\
\text { a) Es una gran fortaleza de mi } \\
\text { profesor(a) } \\
\text { b) Es una fortaleza de mi profesor(a) }\end{array}$} \\
\hline Planeación & 3. Al inicio del curso dialogó con el grupo los objetivos y contenidos del curso & \\
\hline $\begin{array}{l}\text { Estrategias de enseñanza - } \\
\text { aprendizaje }\end{array}$ & 4. Desarrolla actividades que promueven el aprendizaje autónomo & \\
\hline $\begin{array}{l}\text { Estrategias de enseñanza - } \\
\text { aprendizaje }\end{array}$ & $\begin{array}{l}\text { 5. Promueve actividades o experiencias en las que utilizamos argumentos } \\
\text { razonados }\end{array}$ & \\
\hline $\begin{array}{l}\text { Estrategias de enseñanza - } \\
\text { aprendizaje }\end{array}$ & 6. Promueve en mí la reflexión crítica & \\
\hline $\begin{array}{l}\text { Estrategias de enseñanza - } \\
\text { aprendizaje }\end{array}$ & 7. Utiliza recursos y estrategias que me ayudaron a aprender & \\
\hline Ambiente de Aprendizaje & 8. Genera ambientes de trabajo colaborativo (en equipo o en grupos) & \\
\hline Ambiente de Aprendizaje & 9. Me orienta para resolver dudas & \\
\hline Ambiente de Aprendizaje & 10. Promueve un ambiente de respeto & \\
\hline Ambiente de Aprendizaje & 11. Promueve un ambiente para participar con libertad & \\
\hline Evaluación & $\begin{array}{l}\text { 12. Ha hecho comentarios u observaciones a mis entregas o exámenes } \\
\text { (retroalimentación) que enriquecen mi aprendizaje }\end{array}$ & \\
\hline Evaluación & 13. Ha evaluado mi aprendizaje de acuerdo con los objetivos de este curso & \\
\hline Evaluación & $\begin{array}{l}\text { 14. Mediante la retroalimentación, me ayuda a comprometerme con mi } \\
\text { aprendizaje }\end{array}$ & \\
\hline Competencias Profesionales & 15. Relaciona el curso con el quehacer profesional & \\
\hline Competencias Profesionales & 16. Comunica con claridad su conocimiento de la materia & \\
\hline Competencias Profesionales & $\begin{array}{l}\text { 17. Mostró en su actuación o en el desarrollo de sus clases un comportamiento } \\
\text { ético }\end{array}$ & \\
\hline Pregunta control & $\begin{array}{l}\text { 18. Para verificar que sigues leyendo, te pedimos marcar la respuesta "Es un } \\
\text { área donde debe mejorar mi profesor(a)" }\end{array}$ & \\
\hline Ética y valores & 19. Me ayudó a reflexionar sobre las implicaciones éticas de mi actuar & \\
\hline Compromiso Social & $\begin{array}{l}\text { 20. Nos motiva a desarrollar alternativas de acción para promover una mejor } \\
\text { sociedad }\end{array}$ & \\
\hline Compromiso Social & $\begin{array}{l}\text { 21. Me inspira a reconocer mi papel y mi responsabilidad en el desarrollo de una } \\
\text { mejor sociedad (más justa, solidaria, libre, incluyente, productiva y pacifica) }\end{array}$ & \\
\hline Preguntas Globales & 22. Este curso me ayudó a aprender: & $\begin{array}{l}\text { Diferencial Semántico } \\
\text { (Valor de } 1 \text { a } 7 \text { ) } \\
\text { Totalmente en desacuerdo- } \\
\text { Totalmente de acuerdo }\end{array}$ \\
\hline Preguntas Globales & 23. En general el desempeño del profesor(a) tiene... & $\begin{array}{l}\text { Diferencial Semántico } \\
\text { (Valor de } 1 \text { a } 7 \text { ) } \\
\text { Muchas áreas de mejora- Muchas } \\
\text { fortalezas }\end{array}$ \\
\hline No aplica & 24. ¿Qué le sugieres a tu profesor(a) para mejorar su desempeño? & Abierta \\
\hline No aplica & 25. ¿Deseas agregar algún comentario adicional? (Optativa) & Abierta \\
\hline
\end{tabular}

Nota. Elaboración propia.

Se diseñó un reporte de resultados dirigido a docentes del IAE con elementos cualitativos y cuantitativos; su propósito es brindar información útil que retroalimente al profesorado y sea base para el desarrollo de su plan de mejora. Para cada docente está disponible un reporte por cada nivel educativo en el que colabora; además existen reportes diferenciados para los docentes de las modalidades de tutoría y servicio social. El reporte cuenta con los siguientes apartados:

a. Datos generales. Información de las materias que impartió el docente, el número de estudiantes inscritos, el porcentaje de participación en el proceso de evaluación. Así como el porcentaje de los cuestionarios válidos (Figura 4).

b. Resultados por dimensión. En esta sección se ofrece retroalimentación para las preguntas ordenadas por dimensión, según tres niveles de desempeño establecidos a partir de un punto de corte: fortaleza, área de oportunidad conveniente y área de oportunidad prioritaria. Según el 
nivel de desempeño, se ofrecen ideas prácticas que el docente pueda usar para mejorar su actividad docente (Figura 5).

\section{Figura 4}

Ejemplo de sección de datos generales

\section{DATOS GENERALES}

En este apartado se muestra el número de estudiantes que estuvieron inscritos en cada una de tu(s) asignatura(s); el número y el porcentaje de estudiantes que contestaron el cuestionario; el número y el porcentaje de estudiantes que contestaron, pero fueron invalidados ${ }^{1}$; asi como el número y el porcentaje de estudiantes cuyos resultados fueron considerados válidos.

\section{Fundamentos de Programación y Lab.}

Estudiantes en el curso: $8 \quad$ Estudiantes que contestaron: 8
Resultados validos: $8 \quad$ Resultados invalidados: 0

Laboratorio de fundamentos de program.

Estudiantes en el curso: $7 \quad$ Estudiantes que contestaron: 7

Resultados validos: 6 Resultados invalidados: 1

'Los cuestionarios eliminados fueron aquellos en los que se detectó una respuesta incorrecta a lapregunta control o uni respuesta.

${ }^{2}$ Este dato corresponde al numero de estudiantes inscritos menos el numero de estudiantes dados de baja.

Nota. Elaboración propia.

\section{Figura 5}

Ejemplo de la retroalimentación de una de las dimensiones

\section{AMBIENTE DE APRENDIZAJE}

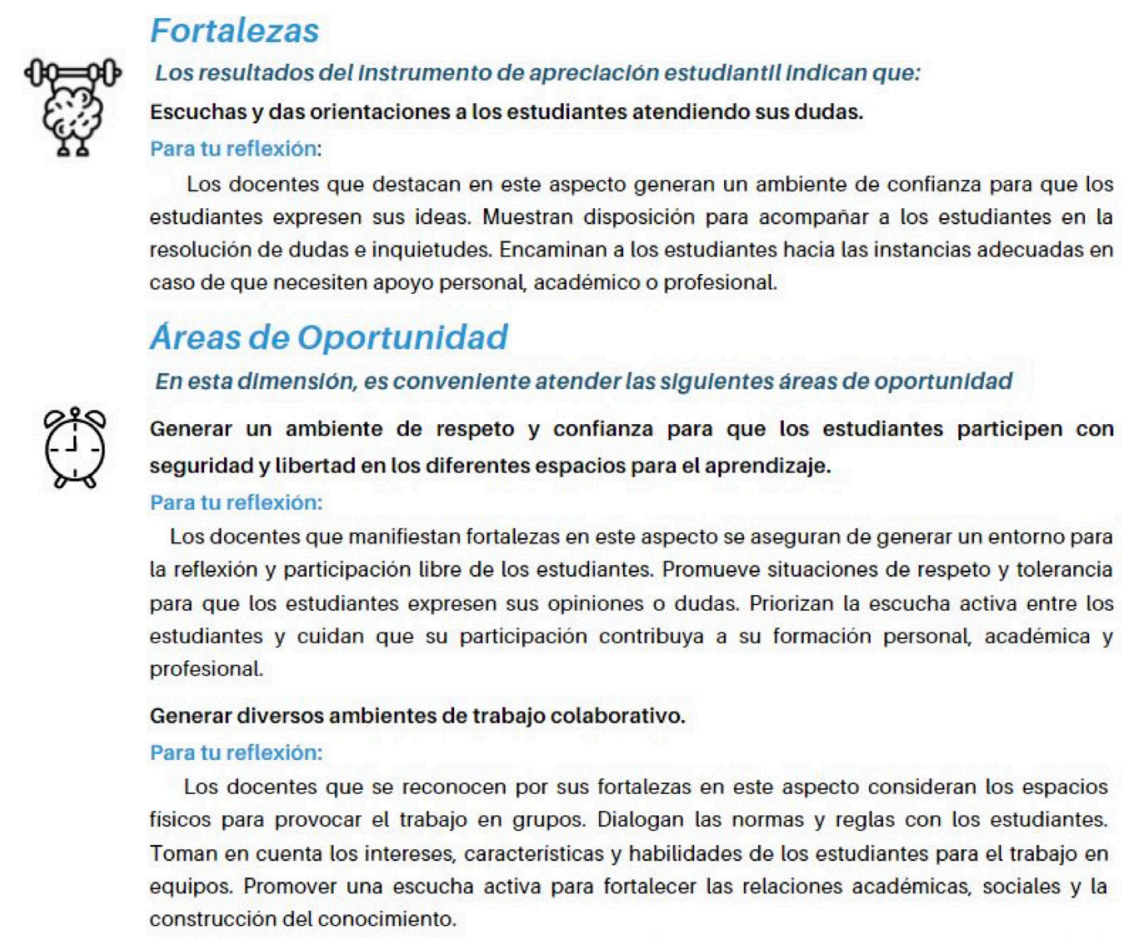

Nota. Elaboración propia. 
c. Principales fortalezas y áreas de oportunidad. En este apartado se indican las principales fortalezas y las áreas de oportunidad que resultan de la evaluación (Figura 6).

Figura 6

Ejemplo de sección 3 de fortalezas y áreas de oportunidad

\section{PRINCIPALES FORTALEZAS Y ÁREAS DE OPORTUNIDAD}

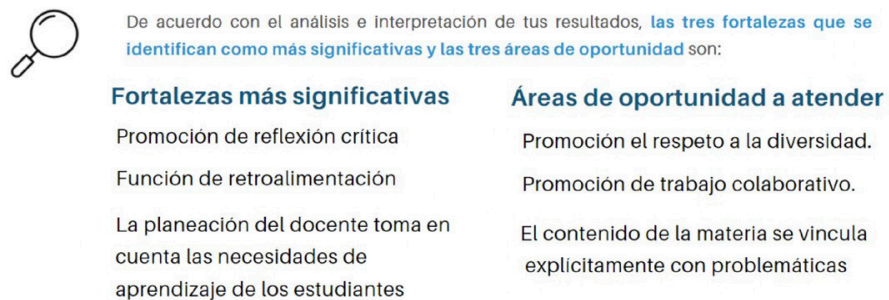

Nota. Elaboración propia.

d. Resultados por grupo. Se incluyen gráficas de respuesta por grupo, para que los docentes puedan identificar las particularidades, semejanzas y diferencias en cada uno de ellos.

e. Respuestas de los estudiantes a preguntas abiertas. En este apartado se incorporan las respuestas que dieron los estudiantes a las preguntas abiertas.

f. Sugerencias para la reflexión personal y el plan de mejora. La finalidad de esta sección es favorecer la reflexión del docente sobre sus resultados; en ella se incluyen preguntas y recomendaciones para enriquecer la reflexión y elaborar un plan de mejora (Figura 7).

Figura 7

Sugerencias para reflexión personal y plan de mejora

\section{SUGERENCIAS PARA LA REFLEXIÓN PERSONAL Y EL} PLAN DE MEJORA

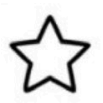

En este reporte se te han ofrecido diversos elementos para analizar tu práctica docente

reflexionar sobre las posibles acciones de mejora que sería recomendable plantearte.

Puedes comenzar por responder las siguientes interrogantes:

1. ¿Que te dicen tus resultados?

2. ¿Cuáles son las principales fortalezas en tu docencia?

3. ¿ue aspectos de tu docencia requieren transformacion?

4. ¿Qué diferencias y similitudes encuentras entre tus grupos? ¿A qué crees que se deban?

5. ¿Qué acciones resultan exitosas? ¿Cuáles no? ¿En que contexto(s) se presentan?

6. ¿Que acciones de formacion podrias llevar a cabo para fortalecer tu docencia, con base en tus principales fortalezas

y áreas de oportunidad?

Para enriquecer tu reflexión y elaborar un plan de mejora, te sugerimos:

- Dialogar con tu coordinador(a) y tus pares académicos.

- Identificar los aspectos de tu docencia que requieren mejora o transformación.

- Considerar las principales fortalezas y las áreas de oportunidad prioritarias identificadas a partir de tus resultados (ver apartado 3).

- Visitar la página del Programa de Desarrollo e Innovación Docente (PDID), donde encontrarás consejos, recursos

y alternativas de formación que te ofrece la Universidad para tu consideracion.

Nota. Elaboración propia. 


\subsubsection{Dialogremos Autoevaluación}

Dialogremos Autoevaluación tiene dos finalidades: 1) promover la reflexión de los docentes sobre sus experiencias durante los cursos impartidos con base en las dimensiones de la docencia a fin de identificar fortalezas y áreas de oportunidad y; 2) reconocer los elementos que caracterizan su práctica docente y con ello, definir sus estilos de docencia.

El instrumento tiene su origen en los indicadores identificados a partir de la revisión teórica. Su propósito es ofrecer información diagnóstica que apoye los procesos de reflexión sobre la práctica docente, por lo que se incluyeron elementos relacionados con prácticas docentes tanto conservadoras como innovadoras.

El instrumento está constituido por ocho secciones. Las primeras siete corresponden a las dimensiones del modelo y la última incluye preguntas orientadas a la reflexión de los docentes. Cada sección inicia con la definición de la dimensión que corresponde, con el objetivo de que el docente conozca lo que sé está evaluando. Las secciones incluyen de una a tres preguntas integradoras, en donde están contenidos los indicadores de la práctica docente referentes a la dimensión en cuestión; y dos preguntas: una abierta y un diferencial en las que se les pide a los docentes que se autoevalúen en esa dimensión. A continuación, se presenta a manera de ejemplo, la sección de la dimensión de planeación con sus preguntas e indicadores (Figura 8).

Figura 8

Vista de la primera sección, con los indicadores

\section{Cuestionario de Autoevaluación}

Instrucciones

- A continuación, aparecen una serie de enunciados organizados en siete dimensiones

- Selecciona en orden de mayor a menor de importancia las opciones con base en lo que realizaste durante tu curso. Elige mínimo una, máximo cuatro

- Puede ser que alguna opción no aplique para tu curso

- Al final de cada sección se presenta una pregunta global para la que te pedimos deslizar el círculo hacia el lado que mejor describa tu respuesta.

Habilidad del docente para diseñar los procesos de enseñanza que propicien el aprendizaje, atendiendo al modelo educativo institucional, el contexto social y las necesidades de los/las estudiantes.

1. Para el diseño de mi curso tomé en cuenta los siguientes elementos:

- los criterios institucionales (Misión, Visión, Ideario, Modelo Educativo)

- la Guía de Estudios Modelo (GEM)

- las particularidades del contexto local, nacional o internacional

- mi experiencia previa en la impartición del curso

- los escenarios de aplicación y de práctica

- el tiempo invertido para elaborar el programa

- el tiempo previsto para desarrollar cada una de las actividades

2. Los elementos que me ayudaron a planear mi curso fueron:

- el perfil de egreso que se pretenden lograr

- la importancia de la asignatura en relación al plan de estudios

- los avances de la disciplina

- los resultados de mis evaluaciones anteriores

- la bibliografía actual relacionada con la materia

- la coherencia de la evaluación con los objetivos y la estrategia de enseñanza y de aprendizaje

3. Otro aspecto o elemento de la planeación que consideraste (especifica):

Considerando el aprendizaje de tus estudiantes, las opciones que marcaste en la dimensión de planeación, dieron un resultado: (semántico de 7 niveles)

Muy favorable 
La última sección del reporte consta de una serie de preguntas abiertas diseñadas para apoyar al docente con la reflexión y la elaboración de un plan de mejora. (Figura 9).

Figura 9

Preguntas de la sección ocho, para orientar la reflexión y apoyar al plan de mejora

\section{REFLEXIÓN Y PLAN DE MEJORA}

29. ¿Qué elementos o situaciones adicionales a lo ya expresado consideras que influyeron en el desarrollo de tu materia?

30. A partir de tus respuestas y tu reflexión, ¿qué acciones propondrías implementar para continuar desarrollando tus fortalezas y atender las áreas de oportunidad que identificaste en este ejercicio de autoevaluación?

31. ¿Cuál crees que se sea el aporte de la autoevaluación a tu práctica docente?

32. ¿Quisieras agregar o comentar algo más?

Nota. Elaboración propia.

Para la definición de los estilos docentes se realizó un análisis de componentes principales, que es un método de reducción de datos. Cada componente es un objeto, resultado de la relación entre indicadores. Se eligió este método con el objetivo de establecer perfiles a partir de las respuestas que dieron los docentes que, a su vez, serviría como diagnóstico para identificar los estilos presentes en la universidad.

Con el ejercicio se obtuvieron un número determinado de componentes para cada dimensión, así como los indicadores ligados a cada uno de ellos. El equipo de trabajo realizó la validación y definición de cada componente a partir de la relación conceptual identificada en los indicadores incluidos en él. Se excluyeron aquellos componentes que tenían pocos indicadores y que ya habían sido retomados en otros componentes o que sólo tenían pesos negativos.

Para reportar los resultados derivados de este instrumento se diseñó un reporte dirigido a docentes con los siguientes elementos:

1. Un perfil de práctica docente. Incluye la descripción del componente predominante de cada dimensión, así como el puntaje para los otros componentes, calculados a partir de las respuestas del instrumento de Autoevaluación. A continuación, se incluyen dos dimensiones, a manera de ejemplo, (Figura 10). 


\section{Figura 10}

Ejemplo del reporte del estilo docente

Estimado(a) XXX (nombre(s),

Te presentamos los resultados del ejercicio de Autoevaluación. Las respuestas que diste al cuestionario son elementos valiosos para tu reflexión sobre el desarrollo de tus cursos, y para analizar tu desempeño docente. Esto, junto con los resultados de la apreciación estudiantil, serán insumos para la elaboración de tu plan de mejora.

Dialogremos está compuesto por siete dimensiones, que se incluyen en la Autoevaluación: Planeación, Estrategias de Enseñanza y Aprendizaje, Ambiente de Aprendizaje, Evaluación del Aprendizaje, Competencias Profesionales, Ética y Valores, y Compromiso Social. Cada dimensión está integrada por distintos componentes que la caracterizan. Ninguno de ellos es más importante que el otro. En tu reporte verás aquellos que predominan en tu práctica docente de acuerdo con tu propia valoración.

El reporte consta de las siguientes secciones:

1. Un perfil de tu práctica docente. Incluye la descripción de tu docencia en cada una de las dimensiones de Dialogremos y muestra el puntaje para los componentes que las conforman, calculados a partir de las respuestas que diste en el instrumento de Autoevaluación.

2. Autoevaluación global por dimensión. Gráfica de tus respuestas generales por dimensión.

3. Respuestas a las preguntas abiertas. Pueden servirte para formalizar tu plan de mejora.

\section{Perfil de la práctica docente}

En la primera columna de la siguiente tabla, encontrarás las siete dimensiones. En la segunda columna se describe el componente en el que obtuviste el puntaje más alto para cada dimensión, de acuerdo con tus respuestas. En la tercera columna, se presenta una gráfica de barras de los puntajes obtenidos en cada uno de los componentes que integran cada dimensión. Te invitamos a explorar los distintos componentes en: dialogremos.ibero.mx

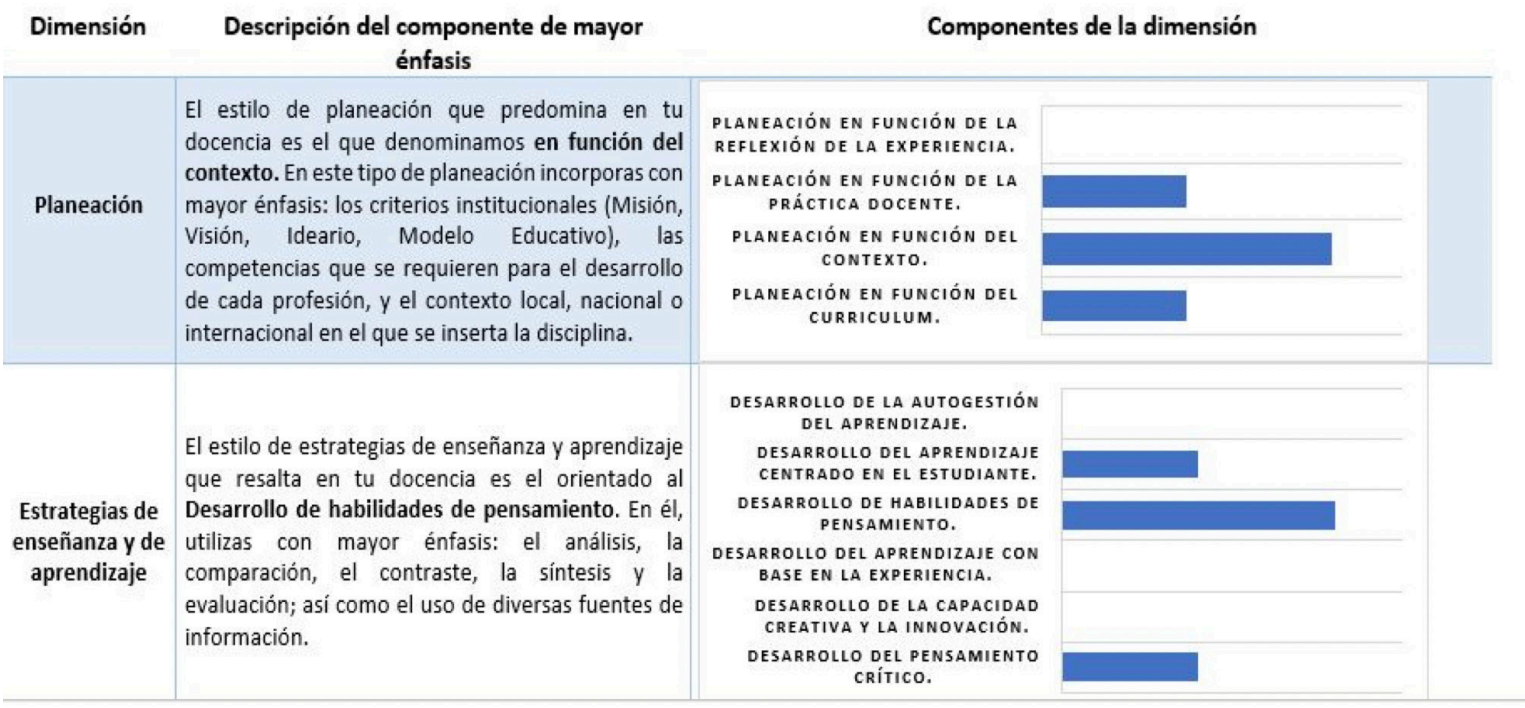

Nota. Elaboración propia.

2. Una gráfica de los resultados globales por cada dimensión (Figura 11). 
Figura 11

Ejemplo de gráfica de autoevaluación por dimensión

\section{Tu autoevaluación global por dimensión}

En este apartado, te presentamos tus respuestas con respecto a la última pregunta en cada dimensión, en la que te pedíamos evaluar el resultado de tu curso considerando el aprendizaje de tus estudiantes. Es una gráfica radial y los puntos más lejanos al centro representan aquellos en los que percibes que tu desempeño fue más eficaz, mientras que los más cercanos al centro son los que identificaste como menos eficaces en este periodo. Esta información te puede servir para contrastar tu percepción con la de los estudiantes, lo que te puede dar indicios acerca de los elementos que puedes mantener o modificar de tu práctica docente.

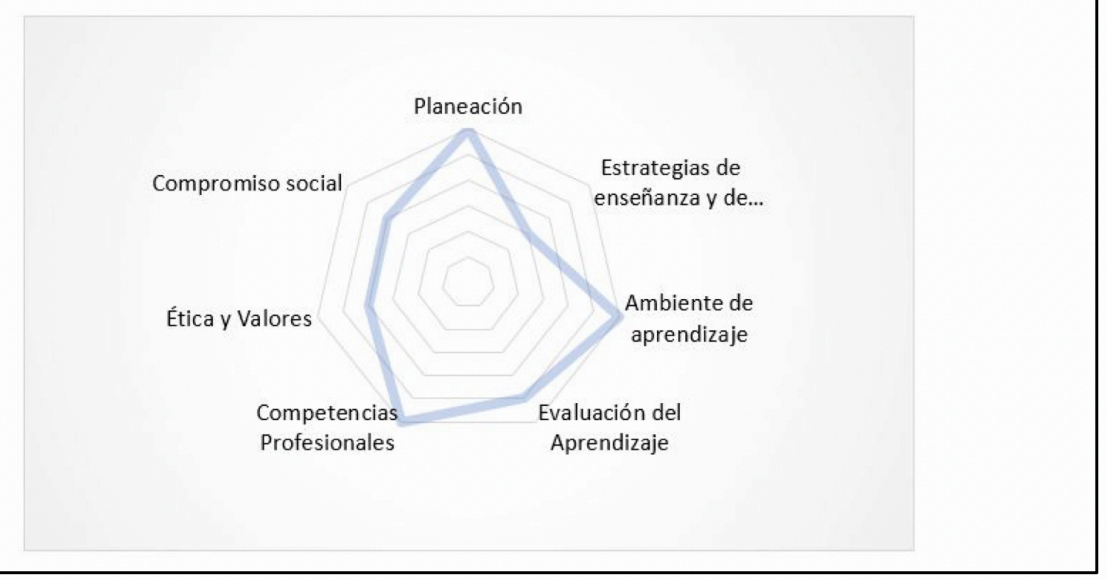

Nota. Elaboración propia.

3. Respuestas a las preguntas abiertas de la autoevaluación.

4. Preguntas orientadoras para la reflexión (Figura 12).

Figura 12

Ejemplo sección de preguntas para elaborar el plan de mejora

\section{Para elaborar tu plan de mejora}

A partir de esta retroalimentación, te invitamos a:

$\checkmark$ Revisar los resultados de la apreciación estudiantil y reflexionar sobre tu desempeño docente, a la luz de tu autoevaluación.

- ¿Qué coincidencias y discrepancias identificas entre los resultados que te acabamos de presentar basados en la percepción que tienes de tu práctica docente y los resultados de la apreciación estudiantil?

- Si tu perspectiva es diferente a la que se reporta en tus resultados de apreciación estudiantil, ¿a qué crees que se deba?

- ¿Qué aspectos de tu práctica docente consideras que debes mantener?

- ¿Qué aspectos de tu práctica docente consideras conveniente mejorar o modificar?

- ¿Qué tipos de apoyos requieres por parte de la lbero o tu coordinación para continuar mejorando?

Nota. Elaboración propia. 


\section{Conclusiones}

Damos a conocer un modelo innovador de evaluación docente en educación superior, con principios y características que lo hacen integral y articulado en torno a siete dimensiones para valorar la docencia.

Es un modelo formativo, ya que ofrece a los profesores información necesaria para analizar y reflexionar sobre su práctica docente, detectar sus fortalezas y áreas de oportunidad, y proponer un plan de mejora que articula acciones de formación, capacitación y actualización orientadas al desarrollo de sus potencialidades. El Modelo promueve el respeto del docente como persona, al impulsar la toma de decisiones para actuar en libertad mediante un proceso transparentado ante toda la comunidad universitaria, y busca revalorizar la práctica docente, lo que repercutirá en mejores, eficientes y pertinentes procesos de enseñanza, que a su vez impulsarán mejores aprendizajes en los estudiantes.

La propuesta es el reflejo de un trabajo colaborativo en el que ha participado la comunidad de docentes, estudiantes y autoridades, y tiene la peculiaridad de contar con el respaldo institucional desde sus fases iniciales de diseño. Uno de los logros del modelo es diversificar las fuentes de información, gracias a la participación de diversos actores a quienes se les da la palabra: estudiantes por medio del instrumento de apreciación estudiantil, docentes mediante la autoevaluación y autoridades con un instrumento específico para ellos, además de la posibilidad de incluir otros instrumentos como el portafolio del docente y la observación en clase.

Para lograr validez y confiabilidad en los instrumentos, se sigue un proceso apegado a lineamientos científicos recurriendo a metodologías cuantitativas y cualitativas.

Busca generar en la comunidad educativa confianza en la forma de evaluar, al transparentar todo el proceso, desde la creación del modelo, sus principios, características y orientaciones, hasta el diseño de los instrumentos, los procesos de aplicación, el uso de resultados y el apoyo para elaborar un plan de mejora. Con esto se pretende generar una cultura de la evaluación en toda la comunidad, al proponer la evaluación como un proceso de mejora de la docencia en el que los estudiantes contribuyen a la reflexión de sus docentes y se involucran activamente en su proceso de enseñanza y de aprendizaje.

La difusión de Dialogremos por canales institucionales, redes sociales y medios impresos ha propiciado la participación activa de los diferentes sectores de la comunidad universitaria, lo que ha propiciado altos porcentajes de respuesta de los instrumentos de evaluación intermedia, apreciación estudiantil y autoevaluación, por lo que se puede afirmar que se cuenta con información confiable.

El apoyo de la Universidad ha sido un factor fundamental en el desarrollo de Dialogremos como un proceso holístico. En este artículo solo se ha comentado la parte correspondiente al diseño del modelo y sus instrumentos y reportes, por lo que se buscarán nuevas oportunidades para difundir los avances en su aplicación y la forma como ha contribuido a mejorar procesos educativos, como consecuencia de una práctica docente más eficiente y pertinente para el contexto de la Ibero.

Con Dialogremos nos encaminamos a ver a la evaluación docente de una manera diferente, construimos Dialogremos para reflexionar y proponer, con base en la revisión de la literatura especializada, una perspectiva de mejora continua, que se encamine a construir una cultura de la evaluación como una realidad, dicho de otra manera, este modelo nos permitió acortar la distancia entre lo deseable y lo posible. Finalmente, con la difusión de Dialogremos queremos aportar información que anime a otras instituciones de educación superior a reencontrarse con la evaluación docente desde otra perspectiva.

\section{Referencias}

Arbesú, M. y García, J. (2017). La evaluación docente en jaque: La visión de los funcionarios universitarios. Revista Iberoamericana de Evaluación Educativa, 10(2), 171-185. https://doi.org/10.15366/riee2017.10.2.009

Ardoino, J. (2000). Consideraciones teóricas sobre la evaluación en educación. En M. Rueda y F. Díaz (Eds.), Evaluación de la docencia. Perspectivas actuales (pp. 23-27). Paidós Educador. 
Cabarrús, C. (2003). El magis ignaciano. Impulso a que la humanidad viva -apuntes a vuelapluma. Diakonia, 107, 34-62.

Caicedo Cavagnis, E. y Zalazar-Jaime, M. F. (2018). Entrevistas cognitivas: revisión, directrices de uso y aplicación en investigaciones psicológicas. Avaliação Psicológica, 17(3), 362-370.

https://doi.org/10.15689/ap.2018.1703.14883.09

Campos, M. A. (2004). Una aproximación sociocultural a los procesos cognoscitivos en el contexto educativo. Perfiles Educativos, 26(104), 7-32.

Contreras, G. A. (2018). Retroalimentación por pares en la docencia universitaria. Una alternativa de evaluación formativa. Formación Universitaria, 11(4), 83-94. https://doi.org/10.4067/s0718-50062018000400083

Comisión Económica para América Latina y el Caribe (2005). Proyecto educativo común de la compañia de Jjsús en América Latina. Comisión Económica para América Latina y el Caribe.

De Dios-Alija, T., García, J. M. y Muñoz-Pérez, S. (2017). Diseño de un modelo de evaluación y desarrollo docente en una universidad privada. Revista Complutense de Educación, 28(1), 61-80.

https://doi.org/10.5209/rev_RCED.2017.v28.n1.48718

Domingo, A. (2013). Práctica reflexiva para docentes. De la reflexión ocasiona a la reflexión metodológica. Publicia.

Duplá, J. (2000). La pedagogía Ignaciana. Una ayuda importante para nuestro tiempo, conferencia sobre pedagogía Ignaciana. Cuadernos Ignacianos, 161, 171-183.

Ford, T. y Hewitt, K. (2020). Better integrating summative and formative goals in the design of next generation teacher evaluation systems. Education Policy Analysis Archives, 28(63), 2-36.

https://doi.org/10.14507/epaa.28.5024

García-Cabrero, B., Loredo, J., Luna, E., Pérez, C., Reyes, R. y Rigo, R. (2011). Algunas consideraciones sobre los aspectos teóricos involucrados en la evaluación de la docencia. En M. Rueda y F. Díaz-Barriga (Eds), La evaluación de la docencia en la universidad. Perspectivas desde la investigación y la intervención profesional (pp. 13-86). Plaza y Valdés Editores.

Gómez L. y Valdés, M. (2019). La evaluación del desempeño docente en la Educación Superior. Propósitos y Representaciones, 7(2), 479-515. https://doi.org/10.20511/pyr2019.v7n2.255

Hattie, J. y Clarke, S. (2018). Visible learning: feedback. Routledge.

Iglesias, M. y Loredo, J. (2017). La evaluación de la docencia en instituciones de Educación Superior: Significado para el docente. http://www.comie.org.mx/congreso/memoriaelectronica/v14/doc/2851.pdf.

Jornet, J. M., Perales, M. J. y González-Such, J. (2020). El concepto de validez de los procesos de evaluación de la docencia. Revista Española de Pedagogía, 78(276), 233-252.

https://doi.org/10.22550/REP78-2-2020-01

Kolvenbach, P. H. y Hans, P. (1993). La Pedagogía ignaciana hoy. Discurso a los participantes del grupo de trabajo sobre la Pedagogía Ignaciana, un planteamiento práctico. Villa Cavalletti. http://pedagogiaignaciana.com/GetFile.ashx?IdDocumento=124

Kolvenbach, P. (2007). Cura personalis. Revista de Espiritualidad Ignaciana, 38(114), 9-17.

Loredo, J. y Romero, R. (2012). Valoración del modelo de evaluación de competencias docentes en la Universidad Iberoamericana Ciudad de México. Revista Iberoamericana de Evaluación Educativa, 5(1e), 159-178.

Montoya, J., Arbesú, I., Contreras, G. y Conzuelo, S. (2014). Evaluación de la docencia universitaria en México, Chile y Colombia: Análisis de experiencias. Revista Iberoamericana de Evaluación Educativa, 7(2e), 15-42.

Ochoa, L. y Moya, C. (2019). La evaluación docente universitaria: retos y posibilidades. Folios, 49, 41-60. https://doi.org/10.17227/Folios.49-9390

Olarte-Arias Y. A., Madiedo-Clavijo, C. N. y Pinilla-Roa A. E. (2019). Evaluación docente como factor de desarrollo profesional desde una pedagogía reflexiva. Revista de la Facultad de Medicina, 67(3), 277-285.

https://doi.org/10.15446/revfacmed.v67n3.62539 
Parra, H., Guzmán, I. y Marín, R. M. (2017). La evaluación y meta evaluación de la docencia universitaria desde la socio-formación. http://www.comie.org.mx/congreso/memoriaelectronica/v14/doc/1758.pdf

Posner, C. (2004). Enseñanza efectiva. Revista Mexicana De Investigación Educativa, 9(21), 277-318.

Romero, T. y Martínez, A. (2017). Construcción de instrumentos de evaluación del desempeño docente universitario desde una perspectiva cualitativa. Revista Universitaria del Caribe, 18(1), 34-43. https://doi.org/10.5377/ruc.v18i1.4800

Rueda, M. (2018). Los retos de la evaluación docente en la universidad. Publicaciones, 48(1),143-159. https://doi.org/10.30827/publicaciones.v48i1.7334

Rueda, M., Luna, E., García, B. y Loredo, J. (2010). La evaluación de la docencia en las universidades públicas mexicanas: Un diagnóstico para su comprensión y mejora. Revista Iberoamericana de Evaluación Educativa, 3(1), 78-92.

Rueda, M., Luna, E., García, B. y Loredo, J. (2011). Resultados y recomendaciones. En M. Rueda (Coord.), Evaluar para controlar o para mejorar? Valoración del desempeño docente en las universidades (pp. 197-222). Bonilla Artigas Editores.

Salazar, J. (2010). Encuesta de satisfacción estudiantil versus cultura evaluativa de la docencia. Revista Iberoamericana de Evaluación Educativa, 3(1), 120-132

Samino-García, R., y Rivero-Gutiérrez, L. (2018). Propuesta metodológica para la innovación y evaluación docente. Journal of Management and Business Education, 1(3), 259-278.

https://doi.org/10.35564/jmbe.2018.0018

Schön, D. (1998). El profesional reflexivo. Cómo piensan los profesionales cuando actúan. Paidós.

Sierra-Chaparro, G. (2020). Sistema integral de evaluación y seguimiento de la práctica docente en la Educación Superior: Estudio de caso en Colombia. Revista Logos Ciencia \& Tecnología, 12(1), 147-162. https://doi.org/10.22335/rlct.v12i1.1044

Universidad Iberoamericana. (1985). Filosofía educativa de la Universidad Iberoamericana. Senado Universitario, 7 de marzo de 1985.

Universidad Iberoamericana. (2010). Marco conceptual para el diseño de planes de estudio del sistema universitario jesuita. UIA.

Universidad Iberoamericana. (2013). Plan estratégico 2013-2020. UIA.

Universidad Iberoamericana. (2018). Plan estratégico rumbo 2030.

http://rumbo2030.ibero.mx/introduccion.html.

Vigotsky, L. (1979). El desarrollo de los procesos psicológicos superiores. Grijalbo.

Zabalza, M. A (2012). El estudio de las buenas prácticas docentes en la enseñanza universitaria. Revista de Docencia Universitaria, 10(1), 17-42. https://doi.org/10.4995/redu.2012.6120.

\section{Breve CV de los/as autores/as}

\section{María de las Mercedes Iglesias Sobero}

Doctora Interinstitucional en Educación por la Universidad Iberoamericana. Actualmente coordina el Programa de Evaluación Educativa en la Dirección de Desarrollo y Acompañamiento Educativo de la Universidad Iberoamericana. Es miembro de la Red Iberoamericana de Investigadores sobre Evaluación de la Docencia (RIIED). Se desempeñó como docente investigador en el Instituto Superior de Ciencias de la Educación del Estado de México. Ocupó una dirección de área en la Junta de Gobierno del Instituto Nacional para la Evaluación de la Educación (INEE), siendo parte del staff de la Consejera Presidenta. Email: maria.iglesias@ibero.mx

ORCID ID: https://orcid.org/0000-0003-0747-9838 


\section{Javier Loredo Enríquez}

Doctorado en Ciencias de la Educación y Maestría en Educación (Universidad René Descartes, Paris V, Sorbonne, Francia). Con revalidación de la UNAM ambos grados. Licenciatura en Pedagogía, Universidad Nacional Autónoma de México. Líneas de investigación: Evaluación de la práctica docente, formación docente, Diseño y evaluación del currículo. Experiencia profesional: Durante muchos años coordinador de posgrado, tanto de maestría como de doctorado en diversas universidades. Ha participado como responsable en el diseño de varios programas de licenciatura, especialidad, maestría y doctorado. Ha participado en evaluaciones de libros de texto, de programas, de planes de estudio y de proyectos de desarrollo. Miembro en comités de evaluación de varios organismos. Consejero editorial y dictaminador en revistas nacionales e internacionales en educación. Docente en el área educativa en licenciatura, maestría y doctorado e investigador Fue Director del Departamento de Educación (2010-2016), Coordinador del Doctorado Interinstitucional en Educación (2005-2011) y (2015-2016), así como de la Maestría en Investigación y Desarrollo de la Educación de la Universidad Iberoamericana, Ciudad de México (2001-2010). Es miembro de la Red Iberoamericana de Investigadores sobre la Evaluación de la docencia RIIED, Evaluador de Programas inscritos en el Padrón Nacional de Programas de Calidad (PNPC) 2017. Evaluador de Estancias Posdoctorales que otorga CONACYT y ha presentado trabajos en congresos nacionales e internacionales. Tiene publicaciones tantos libros, capítulos de libro y artículos en la línea de la evaluación de la práctica docente y currículo. Email: javier.loredo@gmail.com

ORCID ID: https://orcid.org/0000-0002-0620-566X

\section{Virginia Isidra Martínez Cruz}

Maestra en Psicología Escolar por el Posgrado de la Facultad de Psicología de la Universidad Nacional Autónoma de México. Actualmente forma parte del Programa de Evaluación Educativa de la Dirección de Desarrollo y Acompañamiento Educativo (DIDAE), en la Universidad Iberoamericana Ciudad de México. Contribuyó como asesora de temas de psicometría en la Dirección General de Bachillerato Dirección de Sistemas Abiertos de la Secretaria de Educación Pública. Participó como experta en el curso taller: "Aprendizaje centrado en el alumno" dirigido a los profesores de la Universidad de Guadalajara, organizado por el Consejo Mexicano de Investigación COMIE. Y colaboró con el Fondo de Información y Documentación para la Industria como analista de evaluación en el proyecto: Evaluación de conocimientos de la Policía Federal. Email: virginia.martinez@ibero.mx

ORCID ID: https://orcid.org/0000-0002-4974-986X

\section{Raúl Romero Lara}

Doctor en Educación por la Universidad Iberoamericana, Ciudad de México. Maestría en Pedagogía en la Universidad Nacional Autónoma de México y Licenciatura en Pedagogía, Universidad Pedagógica Nacional. Actualmente es académico de tiempo completo en el Departamento de Educación de la Universidad Iberoamericana Ciudad de México, Coordinador de la Maestría en Investigación y Desarrollo de la Educación. Ha sido presidente de la Sociedad de Egresados de Posgrado de la IBERO. Sus líneas de investigación son: Evaluación de la práctica docente, Práctica docente en contextos interculturales, Formación docente e Incorporación de las TIC en procesos educativos. Es miembro de la Red de investigadores de Evaluación de la Docencia (RIED) y Red Iberoamericana de investigadores de Evaluación de la Docencia (RIIED). Colaborador en trabajos de investigación intercultural con comunidades Ráramuris. Docencia en el Instituto Superior Intercultural Ayuuk y en la Universidad del Medio Ambiente. Es coautor de capítulos de libro y artículos publicados en revistas indexadas internacionales en relación a la temática de evaluación de la práctica docente, formación docente e incorporación de las TIC en procesos educativos. Colaboró en el Centro de Estudios Educativos A. C. Email: raul.romero@ibero.mx

ORCID ID: https://orcid.org/0000-0003-4673-2250

\section{Francisco Alvarado Garcia}

Estudió el Doctorado en Educación y la Maestría en Investigación y Desarrollo de la Educación, ambos programas, en la Universidad Iberoamericana, Ciudad de México y la Licenciatura en Psicología en la 
UNAM. En la Universidad Iberoamericana, ha ocupado diversos cargos, actualmente coordina la Maestría en Investigación y Desarrollo de la Educación, así como: "Somos Uno Más: Programa de Inclusión Educativa y Social de Jóvenes con Discapacidad Intelectual" y el Programa "Atención a la Diversidad". En investigación y docencia trabaja las áreas de Evaluación educativa, Psicología educativa, Educación especial y Tecnología aplicada a la educación. Cuenta en su haber con varias publicaciones y ha impartido conferencias a nivel nacional e internacional. Email: franciscoalvarado29@gmail.com

ORCID ID: https://orcid.org/0000-0003-0899-4874

\section{Mariana Sánchez Saldaña}

Doctora en Educación, con más de 35 años de experiencia en docencia de la educación superior, tanto en la Universidad Iberoamericana, como en la Universidad Nacional Autónoma de México. Ha dirigido y coordinado procesos de evaluación, calidad y desarrollo del posgrado en los ámbitos institucional y nacional; ha sido consultora internacional en materia de desarrollo y evaluación del posgrado. En la Ibero fue directora del área responsable de formación y evaluación docente y desarrollo curricular. Actualmente colabora en el Programa de Evaluación Educativa de la Universidad Iberoamericana. Email: mariana. sanchez@ibero.mx

ORCID ID: https://orcid.org/0000-0002-2366-3574 